\title{
Instrumentasi Elektrokardiografi dengan Capacitive Contact Electrode pada Kursi
}

\author{
Monica Regina Emilia, Achmad Arifin, dan Nada Fitrieyatul Hikmah \\ Teknik Elektro, Fakultas Teknologi Industri, Institut Teknologi Sepuluh Nopember (ITS) \\ Jl. Arief Rahman Hakim, Surabaya 60111 \\ e-mail: arifin@ee.its.ac.id
}

\begin{abstract}
Abstrak-Elektrokardiograf secara konvensional menggunakan elektroda Ag-AgCl sebagai conductive contact dan kabel sebagai penghubung antara elektroda dengan elektrokardiograf. Metode yang digunakan bersifat direct sehingga elektroda melekat langsung pada kulit. Konfigurasi ini mengakibatkan ruang gerak pengguna menjadi terbatas dan dalam jangka panjang dapat menyebabkan iritasi pada kulit. Oleh karena itu, pada tugas akhir ini akan difokuskan pada perancangan Instrumentasi Elektrokardiografi secara indirect menggunakan capacitive electrode. Elektroda dibuat dengan menggunakan komponen IC dengan input impedansi tinggi sehingga sinyal jantung dapat direkam walau terhalang oleh pakaian sekalipun. Elektroda dibuat sejumlah 2 buah dan diletakkan pada sandaran kursi, sedangkan untuk ground digunakan PCB berukuran $30 \mathrm{~cm} \times 30 \mathrm{~cm}$ sebagai alas duduk. Ketiga sinyal ini kemudian dilewatkan pada rangkaian penguat instrumentasi, filter dan baseline restoration untuk menguatkan dan menghilangkan komponen sinyal yang tidak diperlukan. Dari pengujian yang telah dilakukan, sinyal QRS complex dapat terdeteksi dengan jelas. Kualitas sinyal yang dihasilkan sangat bergantung dari pakaian yang digunakan. Oleh karena itu capacitive electrode memiliki peluang yang besar untuk dijadikan sebagai elektroda alternatif yang bisa digunakan dalam jangka panjang.
\end{abstract}

Kata Kunci-capacitive electrode, elektrokardiograf, indirect, jantung

\section{PENDAHULUAN}

$\mathbf{J}^{\prime}$ ANTUNG adalah bagian tubuh manusia yang memiliki peran sangat vital. Informasi dari sinyal jantung dapat digunakan sebagai alat untuk menentukan kondisi kesehatan seseorang secara keseluruhan. Namun, tidak banyak orang menyadari pentingnya mengetahui kondisi kesehatan jantung mereka, sehingga ketika mereka merasakan ada sesuatu yang tidak wajar, mereka hanya membiarkan sakit tersebut berlarut-larut hingga akhirnya membahayakan nyawa. Faktanya, data dari WHO menyebutkan bahwa pada tahun 2012, 31\% kematian di dunia disebabkan oleh penyakit kardiovaskular [1].

Seiring dengan semakin berkembangnya teknologi, sinyal jantung saat ini dapat dipantau melalui alat yang disebut dengan elektrokardiograf. Elektrokardiograf konvensional yang banyak digunakan sampai saat ini masih bersifat "fixedon-body" dimana elektroda tersebut terhubung secara direct dengan kulit pengguna. Elektroda ini dapat menghasilkan sinyal jantung dengan kualitas baik. Namun konfigurasi ini kurang cocok untuk digunakan untuk jangka panjang karena dapat mengurangi ruang gerak pengguna dan menyebabkan iritasi pada kulit.

Belakangan telah banyak dikembangkan metode pemantauan sinyal jantung menggunakan elektrokardiograf menggunakan capacitive electrode yang diletakkan pada benda yang berkaitan erat dengan aktivitas sehari-hari manusia seperti kursi [2], kasur[3], [4], bathub [5], dan tempat duduk toilet[6]. Sistem ini mampu menangkap sinyal jantung secara indirect sehingga tidak memerlukan kontak secara langsung dengan kulit pengguna.

Oleh karena itu, dirancang sebuah instrumentasi elektrokardiografi dengan capacitive contact electrode dengan harapan hasil dari penelitian ini dapat menjadi elektroda alternatif untuk instrumentasi elektrokardiografi yang dapat digunakan dalam jangka panjang.

\section{DESAIN SISTEM}

Desain hardware pada kursi dapat dilihat pada Gambar 1. Dua buah elektroda kapasitif diletakkan pada sandaran kursi segaris dengan sadapan left arm dan right arm pada dada dan sebuah lembaran pcb pada alas duduk sebagai ground. Ketiga sinyal ini kemudian dilewatkan pada rangkaian penguat instrumentasi untuk dikuatkan dan filter untuk menghilangkan informasi sinyal yang tidak dibutuhkan. Selain itu, untuk menjaga sinyal agar tetap stabil ditambahkan rangkaian baseline restoration. Selanjutnya sinyal dilewatkan pada rangkaian non inverting adder untuk menaikkan tegangan agar bisa terbaca oleh mikrokontroler.

\section{A. Elektroda Kapasitif}

Elektroda kapasitif dibuat menggunakan dual layer PCB berukuran $4 \mathrm{cmx} 4 \mathrm{~cm}$ setebal $1 \mathrm{~mm}$ dimana salah satu sisi berfungsi sebagai sensing dan terhubung dengan sisi lainnya yang merupakan preamp. IC yang digunakan pada preamp merupakan OPA124U yang memiliki input impedansi tinggi. Pada input juga diletakkan resistor $1 \mathrm{G} \Omega$ secara seri sebanyak 3 buah yang dihubungkan dengan ground sebagai bias current. Skematik rangkaian ditunjukkan pada Gambar 2. Sensor kapasitif sangat dipengaruhi besarnya kapasitansi pakaian yang ditunjukkan pada Persamaan (1).

$$
C=\varepsilon_{0} \varepsilon_{Y} \frac{A}{d}
$$

dimana :

$\mathrm{C}=$ kapasitansi $(\mathrm{F})$

$\varepsilon_{0}=$ permitivitas ruang hampa $\left(8,85418781 . . \times 10^{-12} \mathrm{Fm}^{-1}\right)$ 
$\varepsilon_{y}=$ konstanta dielektrik pakaian yang digunakan

$\mathrm{A}=$ luasan permukaan yang bersentuhan $(\mathrm{m})$

$\mathrm{d}=$ jarak antara elektroda dengan permukaan kulit $(\mathrm{m})$

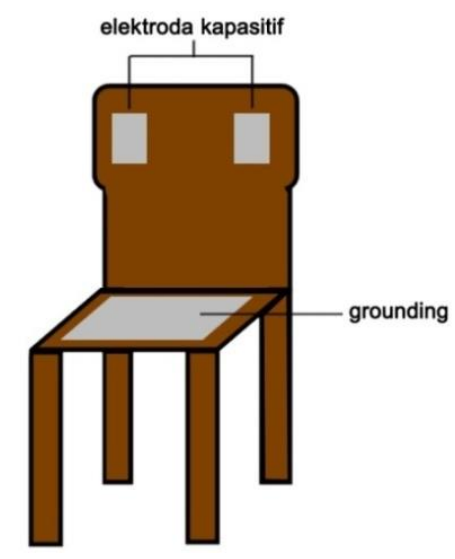

Gambar 1. Konfigurasi pada kursi

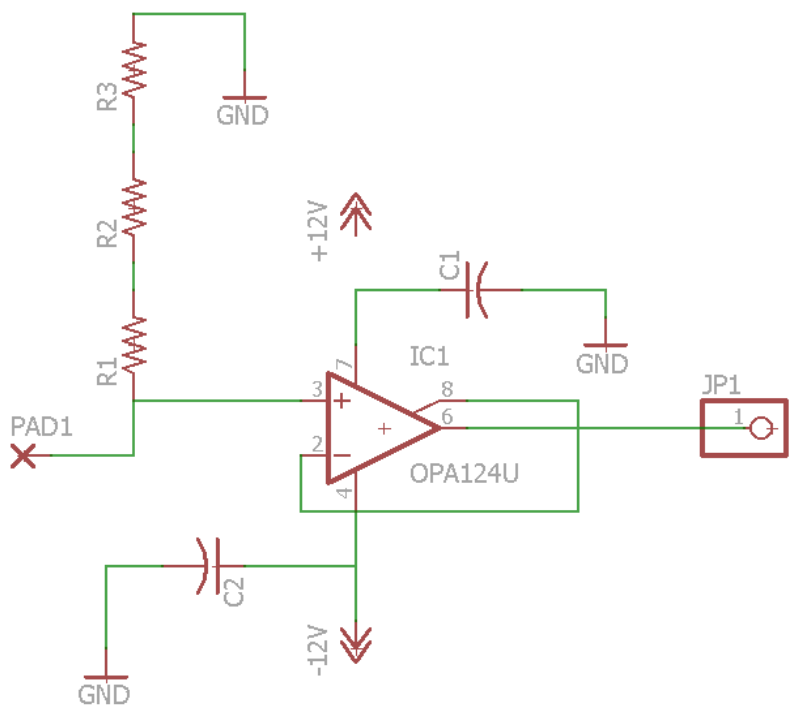

Gambar 2. Skematik capacitive electrode

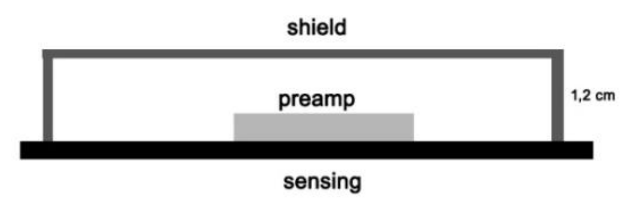

Gambar 3. Konfigurasi elektroda

\section{B. Shield}

Shield berfungsi untuk melindungi rangkaian dari noise yang berasal dari lingkungan sekitar. Bahan yang digunakan adalah kertas karton yang dibentuk menyerupai tudung dan dibungkus dengan alumunium foil dan diletakkan menutupi rangkaian seperti pada Gambar 3. Shield dihubungkan dengan ground.

\section{Grounding}

Pada grounding digunakan one-layer PCB berukuran $30 \mathrm{~cm} \times 30 \mathrm{~cm}$ setebal $1 \mathrm{~mm}$ yang diletakkan diatas tempat duduk. Untuk menjaga ketahanan PCB terhadap beban tubuh, diberikan kayu berukuran $30 \mathrm{~cm} \times 30 \mathrm{~cm}$ setebal $1,5 \mathrm{~cm}$ sebagai pembatas antara kursi dengan PCB.

\section{Penguat Instrumentasi}

Rangkaian penguat instrumentasi terdiri atas 4 bagian utama yaitu low pass filter untuk mengurangi efek gain bandwidth rangkaian op amp, rangkaian proteksi melindungi rangkaian dari tegangan tinggi, rangkaian penguat menggunakan AD620 dan rangkaian drive right leg yang berfungsi memberikan feedback. Nilai penguatan dari AD620 bisa didapatkan dengan memvariasikan nilai $\mathbf{R}_{\mathrm{G}}$ seperti pada Persamaan (2).

$$
\text { Gain }=\frac{49 \cdot 4 \pi \cap}{R_{C}}+1
$$

\section{E. Filter}

Filter digunakan untuk menghilangkan frekuensi sinyal yang tidak dibutuhkan. Filter yang digunakan antara lain low pass filter dan high pass filter dengan pass band $0,5-100 \mathrm{~Hz}$ dan band stop filter $50 \mathrm{~Hz}$ untuk menghilangkan frekuensi jala-jala.

\section{F. Baseline Restoration}

Baseline restoration digunakan untuk menstabilkan sinyal akibat dari pergerakan subjek, interferensi sinyal dari lingkungan, dan berbagai faktor lainnya.

\section{G. Penjumlah tak Membalik (Adder)}

Rangkaian penjumlah tak membalik (adder) bertujuan untuk menaikkan sinyal ECG sehingga range dari sinyal yang tadinya negatif menjadi positif dan bisa terbaca oleh mikrokontroler.

\section{H. $A D C$}

Analog to Digital Converter yang digunakan berasal dari Mikrokontroler STM32F429. Hasil sinyal ditampilkan pada layar mikrokontroler.

\section{HASIL DAN DISKUSI}

\section{A. Pengujian Elektroda Kapasitif}

Pengujian elektroda dilakukan dengan mengalirkan sinyal sinus dengan amplitudo $250 \mathrm{mV}$ dari function generator menuju ke bagian sensing pada elektroda secara langsung tanpa penghalang. Sensor diberi label Sensor A dan Sensor B. Respon dari dua buah sensor menunjukkan penguatan sensor sebesar 3,2. Namun baseline sinyal tidak stabil seperti pada Gambar 4 dan nilai tegangan maksimum dan mininum yang terus berubah-ubah dengan amplitudo $800 \mathrm{mV}$. Oleh karena itu, ditambahkan kapasitor sebagai coupling untuk memblok tegangan DC. Pengujian dilakukan dengan menggunakan berbagai tipe dan nilai kapasitor. Hasil pengujian ditunjukkan pada Tabel 1. Dari pengujian yang dilakukan, kapasitor yang baik untuk digunakan sebagai coupling adalah kapasitor nonpolar karena kapasitor polar tidak mampu memblok tegangan DC. Kapasitor yang dipilih merupakan kapasitor 100 $\mathrm{nF}$ karena kapasitor tersebut menjaga gain tetap stabil. 


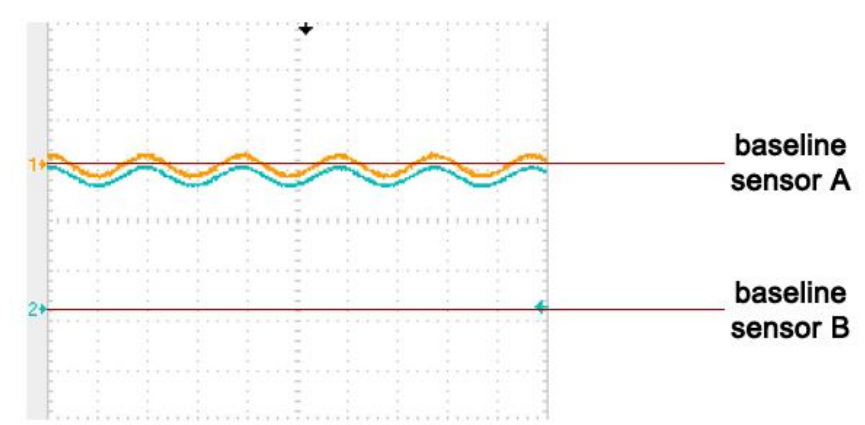

Gambar 4 Baseline yang berbeda untuk sensor A dan sensor B

Tabel 1

Respon sensor dengan coupling kapasitor

\begin{tabular}{|c|c|c|c|c|c|}
\hline \multirow{2}{*}{$\begin{array}{c}\text { Jenis } \\
\text { Kapasitor }\end{array}$} & \multirow{2}{*}{$\begin{array}{c}\text { Nilai } \\
\text { Kapasitor (F) }\end{array}$} & \multicolumn{2}{|c|}{ Sensor A } & \multicolumn{2}{|c|}{ Sensor B } \\
\hline & & $\begin{array}{c}\text { Vpp } \\
(\mathrm{mV})\end{array}$ & Gain & $\begin{array}{c}\text { Vpp } \\
(\mathrm{mV})\end{array}$ & Gain \\
\hline Non Polar & $10 n$ & 0,392 & 1,63 & 0,420 & 1,75 \\
\hline Non Polar & $100 \mathrm{n}$ & 0,760 & 3,17 & 0,780 & 3,25 \\
\hline Non Polar & $1 \mu$ & 0,780 & 3,25 & 0,780 & 3,25 \\
\hline Polar & $10 \mu$ & 0,800 & $\mathrm{TS}^{\mathrm{a}}$ & 0,800 & $\mathrm{TS}^{\mathrm{a}}$ \\
\hline Polar & $47 \mu$ & 0,800 & $\mathrm{TS}^{\mathrm{a}}$ & 0,800 & $\mathrm{TS}^{\mathrm{a}}$ \\
\hline
\end{tabular}

${ }^{\mathrm{a}} \mathrm{TS}=$ tidak stabil

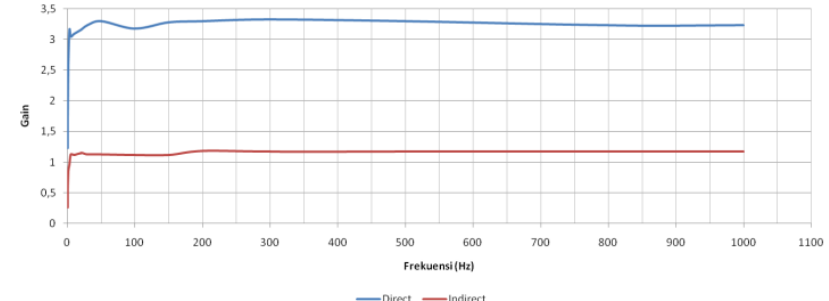

Gambar 5. Respon sensor pengujian direct dan indirect

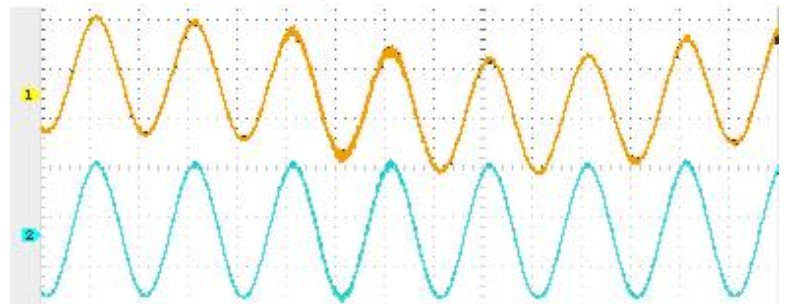

Gambar 6. Perbandingan tanpa shield (atas) dan dengan shield (bawah)

Selanjutnya, respon sensor diuji terhadap perubahan frekuensi dalam 2 kondisi yaitu direct dan indirect dengan penghalang kain dengan tebal $1 \mathrm{~mm}$. Input yang diberikan berupa sinyal sinus dengan amplitudo $228 \mathrm{mV}$. Hasil pengujian pada Gambar 5 menunjukkan bahwa gain saat kondisi indirect menurun hingga 2,7 kali dibandingkan saat kondisi direct.

\section{B. Pengujian Shield}

Pengujian shield dilakukan dengan memberikan interferensi berupa jari dengan jarak $1 \mathrm{~cm}$ dari rangkaian. Hasil pada Gambar 6 menunjukkan bahwa shield dapat melindungi rangkaian dari interferensi sinyal dari luar sehingga sinyal yang dihasilkan menjadi lebih stabil.

\section{Pengujian Penguat Instrumentasi}

Pengujian meliputi pengujian penguatan dan Common Mode Reject Ratio pada IC AD620. Uji penguatan bertujuan untuk membandingkan penguatan secara teoritis dengan saat pengukuran langsung. Percobaan dilakukan saat $R_{G}=900 \Omega$. Pengujian dilakukan dengan pengaturan $\mathrm{V}_{\text {in }}=100 \mathrm{mV}$. Nilai $\mathrm{V}_{\text {out }}=8,2 \mathrm{~V}$ sehingga:

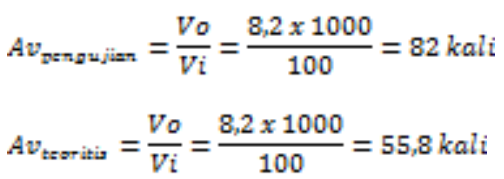

Sedangkan uji CMRR bertujuan untuk mengukur kemampuan IC untuk me-reject sinyal yang tidak diinginkan. Pengujian dilakukan dengan memvariasikan frekuensi dan dicari nilai penguatan saat common mode dan differential mode. Common mode merupakan keadaan dimana nilai tegangan pada input positif dan negatif adalah sama.

Tabel 2

Pengujian CMRR AD620

\begin{tabular}{cccccc}
\hline \hline $\mathrm{fi}(\mathrm{Hz})$ & $\mathrm{Vd}(\mathrm{mV})^{\mathrm{a}}$ & $\mathrm{Vc}(\mathrm{mV})^{\mathrm{b}}$ & $\mathrm{Ad}^{\mathrm{c}}$ & $\mathrm{Ac}^{\mathrm{e}}$ & $\mathrm{CMRR}^{\mathrm{f}}$ \\
\hline 10 & 10400 & 208 & 50 & 1 & 33,979 \\
100 & 10400 & 208 & 50 & 1 & 33,979 \\
250 & 10400 & 208 & 50 & 1 & 33,979 \\
500 & 10400 & 208 & 50 & 1 & 33,979 \\
1000 & 10400 & 208 & 50 & 1 & 33,979 \\
\hline \hline
\end{tabular}

${ }^{\mathrm{a}} \overline{\mathrm{Vd}-T e g a n g a n}$ keluaran differential mode

${ }^{b} \mathrm{Vc}$-Tegangan keluaran common mode

${ }^{\mathrm{C}}$ Ad-Penguatan differential mode

dAd-Penguatan common mode

Sedangkan differential mode merupakan keadaan dimana input positif dialiri tegangan sedangkan input negatif diarahkan menuju ground. Hasil pengujian ditunjukkan pada Tabel 2. Berdasarkan pengujian, nilai CMRR yang didapatkan sebesar 33,979. Hasil ini berbeda jauh dengan yang tertulis pada datasheet yaitu sebesar 1000. Ketidaksesuaian CMRR IC dengan datasheet dapat menyebabkan IC meloloskan dan menguatkan komponen sinyal yang tidak dibutuhkan.

\section{Pengujian Filter}

Filter yang digunakan meliputi low pass filter, high pass filter, dan band stop filter. Sinyal input berupa sinyal sinus dengan amplitudo $500 \mathrm{mV}$ dengan variasi berupa frekuensi. Hasil pengujian filter ditunjukkan pada Gambar 9.

\section{E. Pengujian Baseline Restoration}

Pengujian baseline restoration dilakukan dengan menentukan batas atas dan batas bawah dari masing-masing opamp. Batas atas diatur pada angka $+2 \mathrm{~V}$ dan batas bawah pada $-2 \mathrm{~V}$. Hasil pengujian menunjukkan bahwa saat tegangan input berada dibawah $-2 \mathrm{~V}$, maka relay akan on dan membuat kapasitor discharge lebih cepat dan membuat sinyal kembali ke baseline. Sedangkan saat tegangan berada pada range $-2 \mathrm{~V}$ sampai dengan $+2 \mathrm{~V}$, relay off karena sinyal masih berada pada baseline. Kemudian saat tegangan berada diatas $+2 \mathrm{~V}$, relay kembali ON dan membuat kapasitor discharge lebih cepat dan sinyal kembali ke baseline. 


\section{F. Pengujian Adder}

Penambahan rangkaian adder bertujuan menaikkan level tegangan sinyal agar dapat dibaca oleh mikrokontroler. Pengujian dilakukan dengan input sinyal sinus $520 \mathrm{mV}$. Dari pengujian yang didapatkan didapat selisih $1,75 \mathrm{~V}$ sehingga tegangan dinaikkan sebanyak $1,75 \mathrm{~V}$ ke atas.

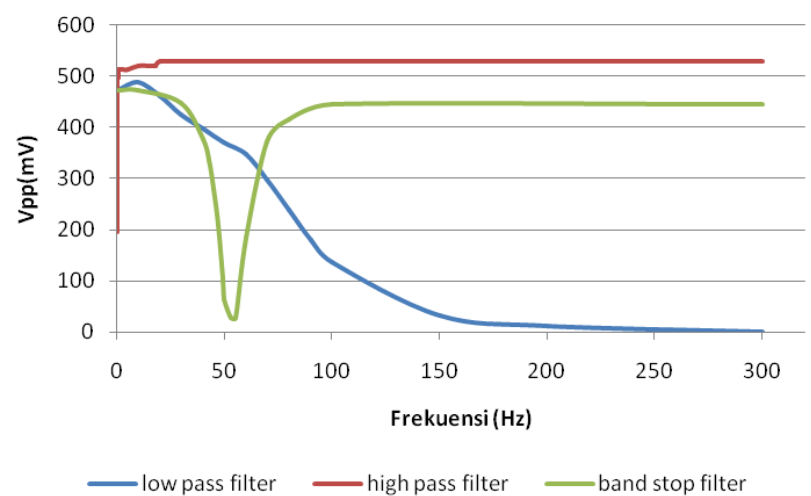

Gambar 7. Respon filter terhadap perubahan frekuensi

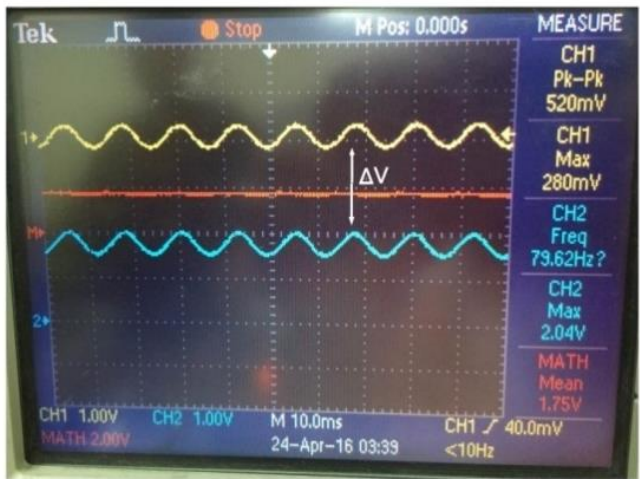

Gambar 8. Pengujian Adder

\section{G. Pengujian Rangkaian Instrumentasi}

Rangkaian instrumentasi terdiri atas rangkaian penguat instrumentasi, filter, baseline restoration dan adder. Pengujian dilakukan menggunakan subjek secara langsung untuk mengetahui efektivitas penggunaan rangkaian baik melalui sadapan pada dada maupun pada punggung. Pengujian dilakukan menggunakan disposable electrode. Peletakan elektroda di punggung sama seperti dengan di dada namun ditembuskan ke belakang seperti pada Gambar 9. Hasil pengujian ditunjukkan pada Gambar 10.

\section{H. Pengujian Sistem Keseluruhan}

Pengujian sistem keseluruhan meliputi sensor yang dihubungkan dengan rangkaian instrumentasi elektrokardiogram. Pengujian dilakukan dengan kondisi subjek menggunakan pakaian dan celana lengkap dan duduk di kursi. Elektroda diletakkan lurus dengan titik sadapan left arm (LA) dan right arm (RA) pada bagian dada.

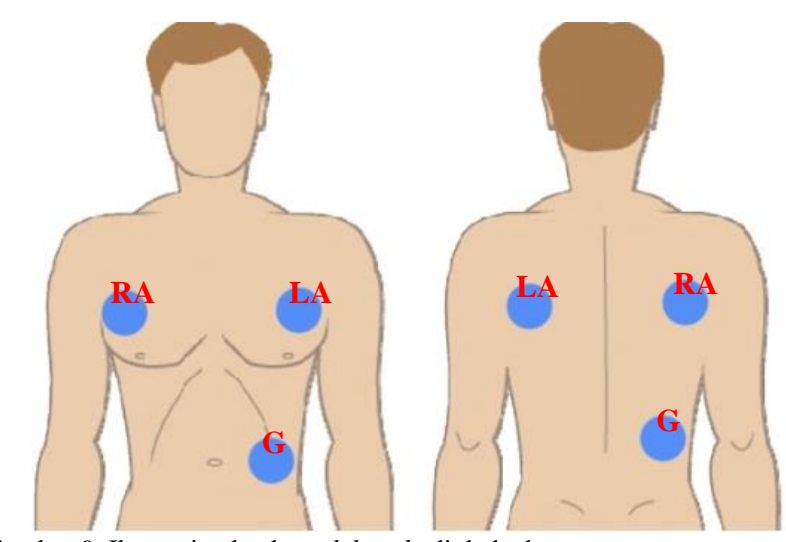

Gambar 9. Ilustrasi peletakan elektroda di dada dan punggung

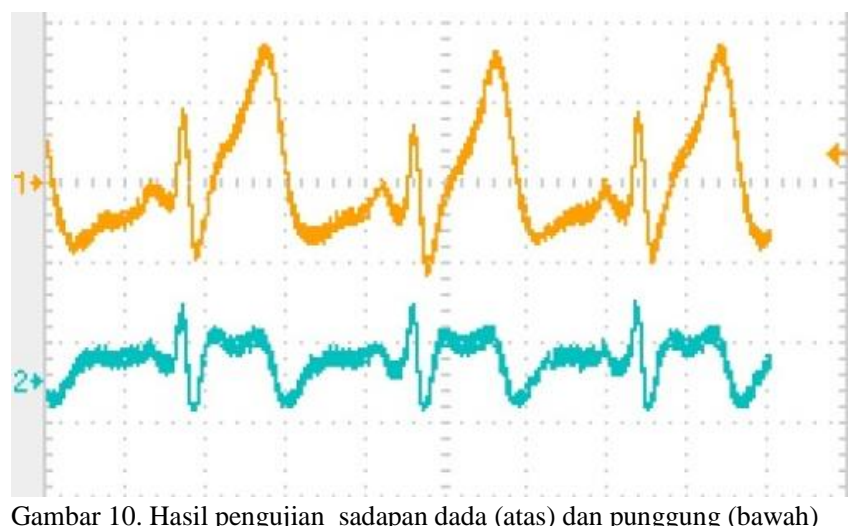

Gambar 10. Hasil pengujian sadapan dada (atas) dan punggung (bawah)

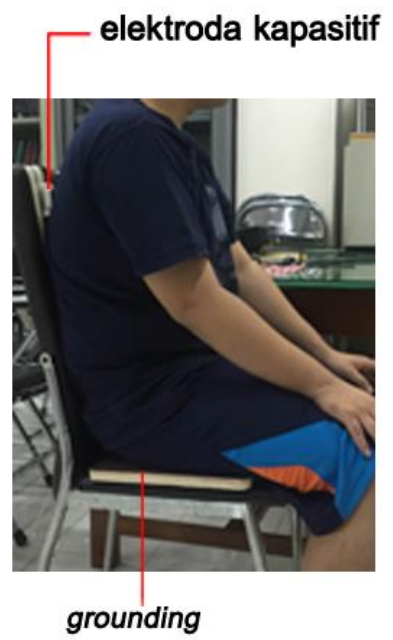

Gambar 11. Konfigurasi pengujian subjek

Pengujian dilakukan pada 3 subjek dengan variabel ketebalan pakaian.

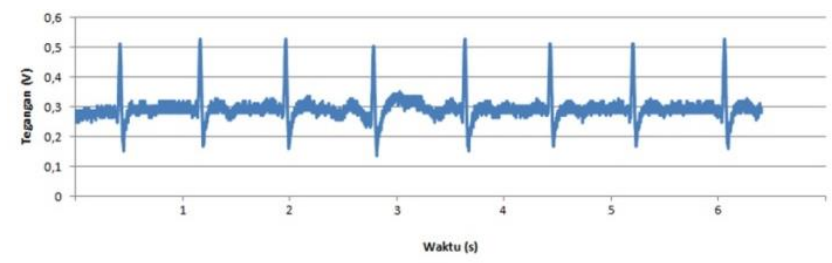

Gambar 12. Subjek menggunakan kemeja (1mm) 


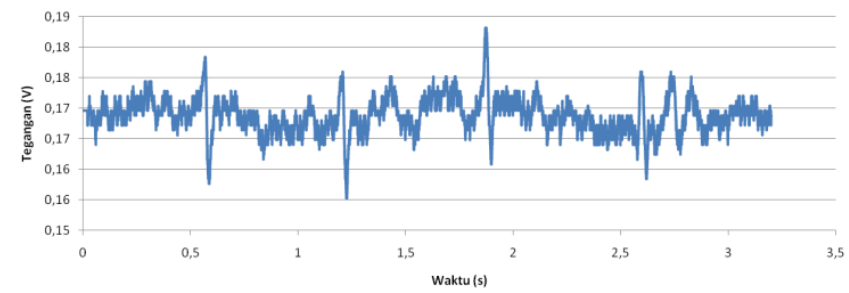

Gambar 13. Subjek menggunakan kaos katun (2mm)

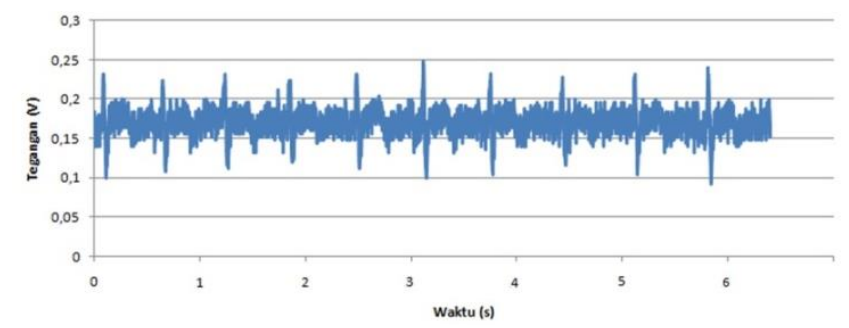

Gambar 14. Subjek menggunakan jaket (3mm)

Dari pengujian yang dilakukan dapat dilihat bahwa QRS complex untuk setiap kondisi pakaian masih dapat terdeteksi dengan baik. Namun semakin tebal pakaian yang digunakan, semakin rendah pula kualitas sinyal yang dihasilkan. Hal ini dikarenakan semakin jauh jarak antara elektroda dengan permukaan kulit, semakin banyak noise yang tertangkap dan ikut terekam.

\section{KESIMPULAN}

Instrumentasi elektrokardiogram menggunakan capacitive electrode tidak memerlukan kontak langsung dengan kulit pengguna. Metode ini menggunakan elektroda yang diletakkan pada sandaran kursi dan grounding pada alas duduk. Kualitas sinyal yang dihasilkan masih dibawah sinyal dengan metode direct menggunakan disposable electrode dan bergantung dengan pakaian yang digunakan. Namun QRS complex masih dapat dideteksi dengan baik sehingga metode ini berpotensi untuk digunakan sebagai instrumen elektrokardiografi yang nyaman untuk digunakan sehari-hari.

\section{DAFTAR PUSTAKA}

[1] World Health Organization, Januari 2015. "Cardiovascular Disease". <http://www.who.int/mediacentre/factsheets/fs317/en/>. Februari 2016.

[2] Lim, Yong Gyu., Kim, Ko Keun., Park, Kwang Suk., Mei 2006. "ECG Measurement on a Chair Without Conductive Contact". IEEE Transaction on Biomedical Engineering, Vol. 53, No. 5.

[3] M. Ishijima, Juni 1993. "Monitoring of Electrocardiograms in Bed Without Utilizing Body Surface Electrodes." IEEE Transaction on Biomedical Engineering, Vol. 40, PP. 573-579.

[4] Lim, Yong Gyu., Kim, Ko Keun., Park, Kwang Suk., April 2007. "ECG Recording on a Bed During Sleep Without Direct Skin-Contact". IEEE Transactions on Biomedical Engineering, Vol. 54, No.4.

[5] Lim, Yong Gyu., Kim, Ko Keun., Park, Kwang Suk., September 2004 "ECG Measurement in The Bathub Using The Insulated Electrodes", Proceeding 26th Annual IEEE EMBS Conference in San Fransisco, pp.2383-2385.

[6] Lim, Yong Gyu., Kim, Ko Keun., Park, Kwang Suk., September 2004. "The Electrically Noncontacting ECG Measurement on The Toilet Seat Using The Capacitively-Coupled Insulated Electrodes". Proceeding 26th Annual IEEE EMBS Conference in San Fransisco, pp.2375-2378. 